\title{
Antitumor activity of methoxylated flavonoids separated from Achillea fragrantissima extract in Ehrlich's ascites carcinoma model in mice
}

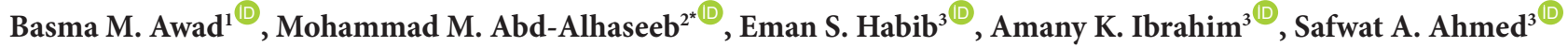 \\ ${ }^{1}$ Department of Pharmacognosy, Faculty of Pharmacy \& Pharmaceutical Industries, Sinai University, Arish, Egypt \\ ${ }^{2}$ Department of Pharmacology and Toxicology, Faculty of Pharmacy, Damanhour University, Al-Buhaira, Egypt \\ ${ }^{3}$ Department of Pharmacognosy, Faculty of Pharmacy, Suez Canal University, Ismailia, Egypt
}

\section{A R T I C L E IN F O}

Article Type:

Original Article

\section{Article History:}

Received: 2 March 2019

Accepted: 17 May 2019

\section{Keywords:}

Achillea fragrantissima

Cirsimaritin

Chrysosplenol D

Cirsiliol

Eupatilin-7-methyl ether

Ehrlich's ascites carcinoma

\begin{abstract}
A B S T R A C T
Introduction: Achillea fragrantissima extract has been used in folk medicine as anticancer. The present study describes the antitumor activities of the extract and the flavonoid compounds and attempts to explain the mechanisms underlying these activities.

Methods: The whole plant of A. fragrantissima was collected and ground to produce a fine powder which subjected to maceration process. Step gradient elution was used using silica gel vacuum liquid chromatography (VLC). The fractions were compared by thin layer chromatography (TLC) and concentrated. Final purification was performed using Sephadex LH-20 to give three compounds cirsiliol, chrysosplenol D and cirsimaritin from F4 and one compound, eupatilin-7-methyl ether from F6. In this study, Ehrlich's ascites carcinoma (EAC) model was used as the model of cancer.

Results: Achillea fragrantissima extract and its isolated methoxylated flavonoids significantly reduced the weight of tumor discs compared to EAC-control group. In addition, cirsimaritin and eupatilin 7-methyl ether treatments produced a dose-dependent reduction in tumor weight. Serum tumor necrosis factor-alpha (TNF-a) level showed that $A$. fragrantissima extract and its isolated methoxylated flavonoid compounds significantly reduced its serum level compared to the EAC-control group. Furthermore, A. fragrantissima extract and the flavonoids significantly increased the Total antioxidant capacity (TAC) compared to EAC-control. A. fragrantissima extract and its isolated methoxylated flavonoids produced a better differentiation of tumor cells, with reduced nuclear pleomorphism and better formed tubular structures especially with high dose indicating the induction of apoptotic mechanism.

Conclusion: Achillea fragrantissima extract and its isolated methoxylated flavonoids exhibit antitumor activities that may be attributed to the antioxidant properties and the induction of the apoptotic process.
\end{abstract}

Implication for health policy/practice/research/medical education:

This paper approved the antitumor activities of A. fragrantissima extract and its separated methoxylated flavonoids in animal models. In addition, it was concluded that the extract possesses antitumor activity through apoptosis and antioxidant activities. Please cite this paper as: Awad BM, Abd-Alhaseeb MM, Habib ES, Ibrahim AK, Ahmed SA. Antitumor activity of methoxylated flavonoids separated from Achillea fragrantissima extract in Ehrlich's ascites carcinoma model in mice. J Herbmed Pharmacol. 2020;9(1):28-34. doi: 10.15171/jhp.2020.04.

\section{Introduction}

Herbal preparations have been used in the treatment of various diseases since ancient times, and have become an important source for drug discovery in recent decades (1). Herbal extracts and isolated compounds both have been investigated for their antitumor activities by interfering with the development and progression of cancer through various mechanisms (2).

Achillea fragrantissima (Forssk.) Sch. Bip. (Asteracaea) is widely distributed in many countries, local people in folk or traditional herbal medicines have used Achillea species in the treatment of several diseases such as gastrointestinal problems and inflammatory conditions (3). Phytochemical investigation of Achillea, species has 
shown many bioactive compounds including flavonoids, volatile oils, terpenoids, lignans, amino acid derivatives, fatty acids and many other known compounds (4). A. fragrantissima, also known in Arabic countries as lavender cotton or in many cases as Qaysūm, is a desert plant. In addition, $A$. fragrantissima was reported to be a potent differentiation inducer and in the same time apoptosis and cell cycle arrest activator in both chronic myeloid leukemia and $\mathrm{T}$ cell lymphoma $(5,6)$.

It was therefore thought worthwhile to investigate the antitumor effects of $A$. fragrantissima extract and its methoxylated flavonoid compounds on Ehrlich's Ascites Carcinoma model in mice, the effects that have not been studied to date. The methanolic extract of $A$. fragrantissima growing in Egypt was investigated for its flavonoid contents. Four methoxylated flavonoids were isolated from the extract, namely chrysosplenol D, cirsiliol, cirsimaritin, and eupatilin-7-methyl ether. The methoxylated flavonoids have been used as a dietary supplement in cancer prevention (7). In addition, the antiproliferative activities of these flavonoids have been reported and can be considered a promising target for new researches (6-9). The present study described the antitumor activities of the extract and the flavonoid compounds and attempted to explain the mechanisms underlying these activities.

\section{Materials and Methods}

Plant collection

Achillea fragrantissima aerial parts were collected from WadiElarbaen, Sinai Peninsula, Egypt and identified by Prof. Abd El-Raouf Moustafa, Professor of Botany, Faculty of Science, Suez Canal University, Ismailia, Egypt. A voucher specimen of the plant was deposited in the herbarium section of Pharmacognosy Department, Faculty of Pharmacy, Suez Canal University, Egypt (\# SAA-108).

\section{Extraction and fractionation}

Achillea fragrantissima aerial parts $(3 \mathrm{~kg}$ ) were ground to a fine powder and extracted with methanol by maceration method at room temperature. The resultant was filtered and then evaporated to dryness. This dried extract was subjected to silica gel vacuum liquid chromatography (VLC) using step gradient elution ( $n$-hexane/ethyl acetate/methanol) to achieve 7 fractions (2 L each), labeled F1 to F7. The fractions were compared by TLC and concentrated.

Isolation of bioactive compounds

Further purification for the fractions F4 (39 g) and F5 $(64.73 \mathrm{~g})$ was performed using column chromatography technique. The fractions were loaded on silica gel which was packed in an open column then chromatographed using gradient elution ( $n$-hexane/ethyl acetate/methanol).
The resulting sub-fractions were monitored by TLC then further purification was carried out using flash silica chromatography.

Final purification was performed using Sephadex LH-20 to give the methoxylated flavonoids eupatilin-7methyl ether, chrysosplenol D and cirsiliol from F4 and cirsimaritin from F5.

Drugs, chemicals, and instruments

Cisplatin was purchased from Sigma-Aldrich (St. Louis, MO, USA). Dimethylsulfoxide (DMSO), sodium chloride $(\mathrm{NaCl})$, hematoxylin and eosin $(\mathrm{H} \& \mathrm{E})$ solutions were purchased from Sigma-Aldrich (St. Louis, MO, USA). Enzyme-linked immunosorbent assay (ELISA) kit for tumor necrosis factor-alpha (TNF-a) was purchased from Glory Science Co., Ltd (Del Rio, TX, USA). Total antioxidant capacity (TAC) kit was purchased from Labor Diagnostika Nord Co., (Germany). All other chemicals were supplied in analytical grades from commercial sources. Normal phase silica gel $60 \AA$, 70-230 mesh for column chromatography and silica gel $60 \AA$, 230-400 mesh for flash chromatography were purchased from Sigma-Aldrich (Fluka Analytical, Sigma-Aldrich). ${ }^{1} \mathrm{H}$ NMR (500 MHz), ${ }^{1} \mathrm{H}$ NMR (400 MHz), ${ }^{13} \mathrm{C}$ NMR (100 $\mathrm{MHz}$ ), 2D-NMR and DEPT-135 spectra were recorded on a Varian AS 400 (residual solvent signal was used as an internal standard). Lipophilic Sephadex LH-20 (25-100 $\mu \mathrm{m}$ Sigma-Aldrich) was used for column chromatography. Also, percolated aluminum sheets $[0.25 \mathrm{~mm}$ silica gel 60 F254 (Merck, Darmstadt, Germany)] were used for TLC $(20 \times 20 \mathrm{~cm})$.

\section{Animals}

Healthy female albino mice (20-25 g) were used throughout the experiment. They were purchased from the Modern Veterinary Office for Laboratory Animals (Cairo, Egypt) and kept under ethical laboratory conditions $\left(25 \pm 1^{\circ} \mathrm{C}\right.$ temperature and relative constant humidity using air conditioner), in plastic cages. During the whole experiments, the animals were allowed for food and water ad libitum. Protocols of the experiments were approved by The Animal Care and Ethical Committee at the Faculty of Pharmacy, Suez Canal University (Ethical code is 201905RA1).

Solid tumors induction

Ehrlich's ascites carcinoma (EAC) is referred to as an undifferentiated carcinoma which resembles tumors appearing in human and is widely used in many studies as a model to evaluate and determine the antitumor effect of natural compounds $(10,11)$. EAC cell line was purchased from National Cancer Institute, Cairo University, Cairo in Egypt. Aseptic conditions were used in all steps of EAC preparation. Suspension of EAC cells was prepared using normal saline to reach the concentration of 2.5 million 
EAC cells in $0.1 \mathrm{~mL}$ suspension. Mice were inoculated intradermally with $0.1 \mathrm{~mL}$ of the EAC suspension $(2.5$ $\times 10^{-6}$ cells in $0.1 \mathrm{~mL}$ ) on the first day of the experiment (12).

\section{Experimental design}

One hundred and two mice were allocated randomly into seventeen groups. Each group contained six mice. Tumor growth 8 days after tumor inoculation was confirmed and the groups designated as follows. Group I: normal mice that were received saline orally $(0.15 \mathrm{~mL} / \mathrm{mice} / \mathrm{d}$, orally). Group II: received saline and bearing tumor discs, served as the EAC-control (Positive control) group. Group III: injected with cisplatin (5 mg/kg/wk, i.p.) (13). Groups IV-V: received $A$. fragrantissima methanolic extract (100 or $200 \mathrm{mg} / \mathrm{kg} / \mathrm{d}$, orally). Groups VI-VII: treated with chrysosplenol D (5, 10 or $20 \mathrm{mg} / \mathrm{kg} / \mathrm{d}$, orally). Group IX-XI: treated with cirsiliol (5, 10 or $20 \mathrm{mg} / \mathrm{kg} / \mathrm{d}$, orally). Groups XII-XIV: treated with cirsimaritin (5, 10, $20 \mathrm{mg} /$ $\mathrm{kg} / \mathrm{d}$, orally), respectively. Groups XV-XVII: treated with eupatilin-7-methyl ether (5, 10 or $20 \mathrm{mg} / \mathrm{kg} / \mathrm{d}$, orally). Achillea fragrantissima methanolic extract and the isolated flavonoids were administered orally by gastric gavage daily in a volume of $5 \mathrm{~mL} / \mathrm{kg}$, whereas cisplatin was injected intraperitoneally. All injections were launched on day 8 and continued for 14 days.

Serum samples preparations, isolation of tumor discs and histopathological examinations

Blood samples were withdrawn from the retro-orbital plexus of each animal in a non-heparinized tube on the last day of the experiment. After clotting, the tubes containing the blood were centrifuged at $4000 \mathrm{rpm}$ (Universal 32R, Germany) and $4^{\circ} \mathrm{C}$ for 15 minutes. The separated sera were stored at $-20^{\circ} \mathrm{C}$ until used for estimation of total antioxidant capacity (TAC) and TNF-a. Then, the animals were sacrificed by cervical dislocation and tumor discs were dissected, weighed and fixed in 10\% phosphatebuffered formalin. All paraffin-embedded tissues were sectioned at $4 \mathrm{~mm}$ and prepared for hematoxylin and eosin (H\&E) staining. The histological assay was performed by $\mathrm{H} \& \mathrm{E}$ staining.

\section{Determination of serum TNF- $\alpha$}

Serum TNF- $\alpha$ levels were determined using the ELISA kit. The assay was carried out following the instructions of the manufacturer and the color intensity was measured at 450 nm using a microplate reader (Metertech, M960).

Determination of serum TAC

Antioxidant capacity (TAC) was measured according to the method of Koracevic (14).

Data analysis and statistics

Data in this study were presented as mean \pm standard error of the mean (SEM). Statistical Package for Social Sciences (version 2 for Windows, SPSS Software, SPSS Inc., Chicago, USA) was used to analyze the results of this study. Multiple comparisons of tumor weight, serum TNF-a, and serum TAC were achieved using one-way analysis of variance (ANOVA), which determine significant level followed by a post hoc test named Bonferroni for multiple comparisons.

\section{Results}

Structure elucidation and identification of isolated compounds

Four compounds were isolated and structurally elucidated based on the spectroscopic methods $\left({ }^{1} \mathrm{H} \mathrm{NMR},{ }^{13} \mathrm{C}\right.$ NMR, DEPT and 2D-NMR) and comparing with available literature data. Compounds 1, 2, 3 and 4 are known flavonoids and shown in Figure 1.

\section{Tumor weight}

Cisplatin $(5 \mathrm{mg} / \mathrm{kg})$ and A. fragrantissima extract (100 or $200 \mathrm{mg} / \mathrm{kg}$ ) were shown to significantly decreased the tumor weight in comparison to EAC-control group (Figure 2). In addition, chrysosplenol $\mathrm{D}$ treatment showed a significant reduction in the tumor weight when compared with EAC-control group, especially when used in a dose of $20 \mathrm{mg} / \mathrm{kg}$ that showed a significant reduction when compared with a cisplatin group as well as the other chrysosplenol groups (Figure 3).

Cirsiliol treatment reduced tumor weight compared to EAC-control mice as shown in Figure 4, especially the large dose $(20 \mathrm{mg} / \mathrm{kg})$ which produced a significant reduction when compared to cisplatin and other cirsiliol groups (Figure 4). On the other hand, the cirsimaritin treatment produced a dose-dependent reduction in tumor weight when compared with EAC-control and cisplatin groups

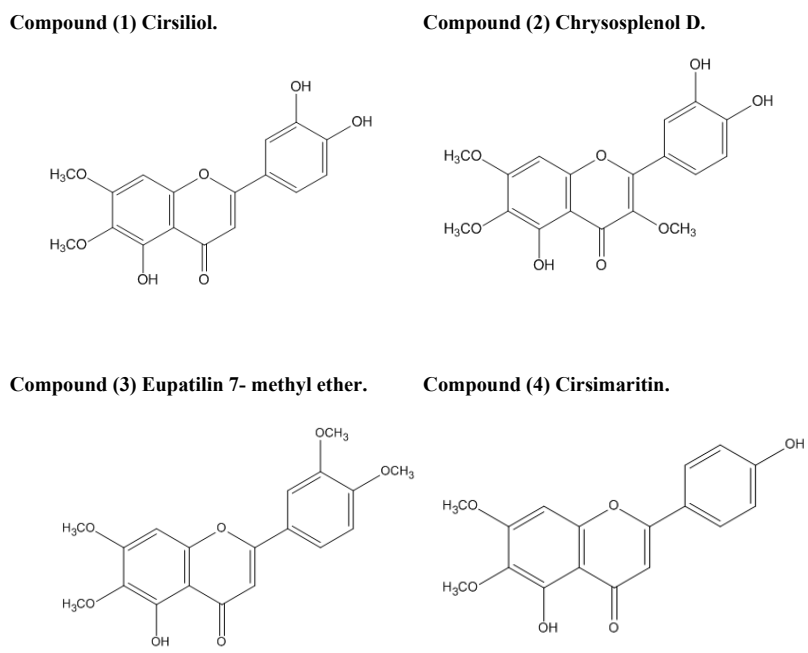

Figure 1. Structures of the methoxylated flavonoids separated and identified from Achillea fragrantissima extract. 


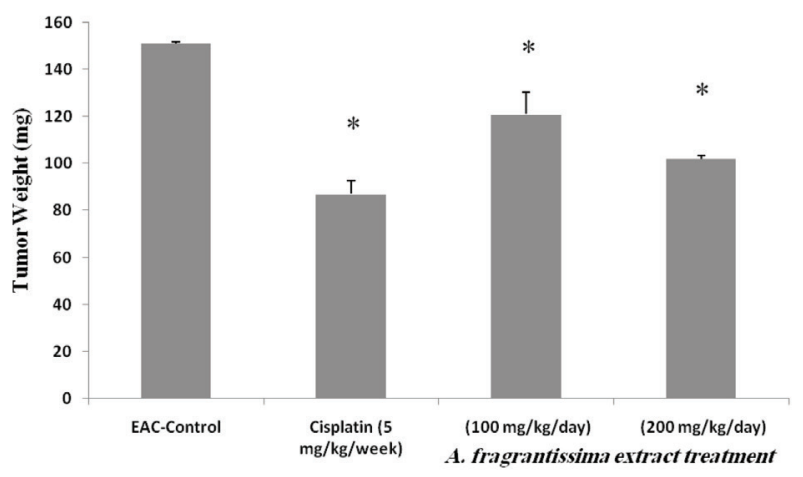

Figure 2. Effects of cisplatin and Achillea fragrantissima extract on tumor weight in EAC-bearing mice. EAC: Ehrlich's ascites carcinoma. Values are expressed as the mean \pm SEM and data were analyzed using one-way ANOVA followed by Bonferroni's post hoc test at $P<0.05$. *Significantly different from the EAC-control.

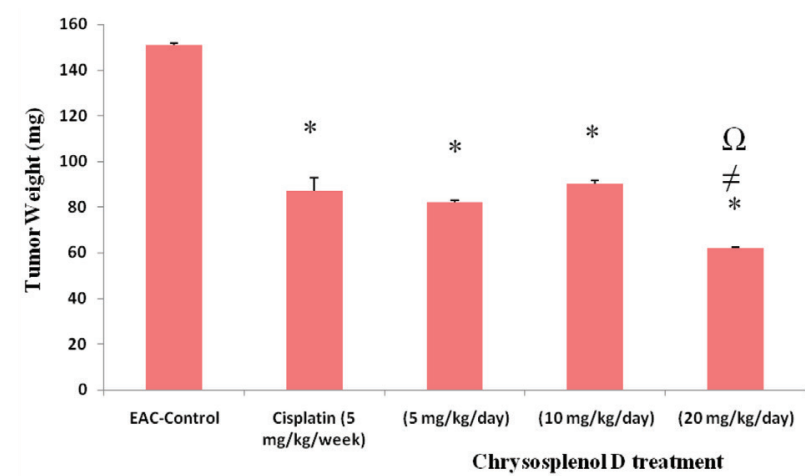

Figure 3. Effect of cisplatin and chrysosplenol D on tumor weight in EACbearing mice. EAC: Ehrlich's ascites carcinoma. Values are expressed as the mean \pm SEM and data were analyzed using one-way ANOVA followed by Bonferroni's post hoc test at $P<0.05$. *Significantly different from the EAC-control. " Significantly different from cisplatin group. ${ }^{2}$ Significantly different from other chrysosoplenol D groups.

(Figure 5). Similarly, Eupatilin 7-methyl ether produced a dose-dependent reduction in tumor weight (Figure 6).

Serum level of TNF- $\alpha$

Determination of serum TNF-a level highlighted that A. fragrantissima extract and its isolated methoxylated flavonoid compounds significantly reduced the serum level compared to the EAC-control group (Table 1). Furthermore, cirsiliol (20 mg/kg), cirsimaritin (20 mg/kg) and eupatilin 7-methyl ether (5, 10 and $20 \mathrm{mg} / \mathrm{kg}$ ) groups produced a significant reduction in serum level of TNF-a compared to all other groups including normal group as shown in Table 1.

Serum level of TAC

The total antioxidant capacity of the A. fragrantissima extract and the isolated compounds were determined and compared to EAC-control mice as shown in Table 1. A.

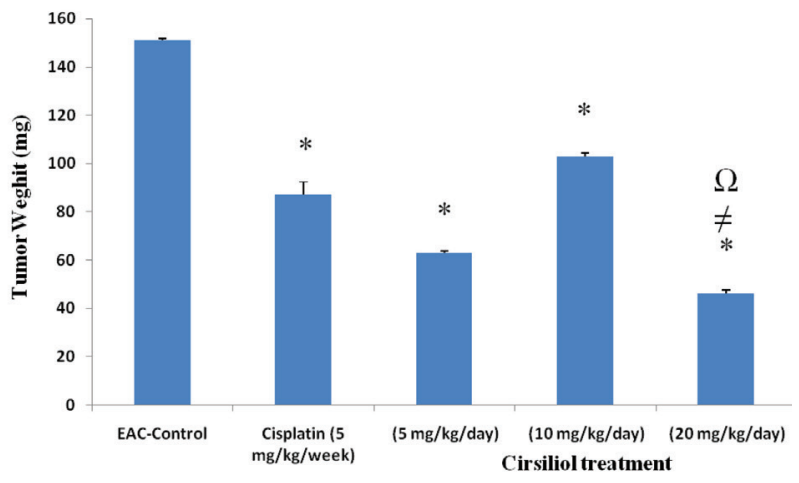

Figure 4. Effects of cisplatin and cirsiliol on tumor weight in EAC-bearing mice. EAC: Ehrlich's ascites carcinoma. Values are expressed as the mean \pm SEM and data were analyzed using one-way ANOVA followed by Bonferroni's post hoc test at $P<0.05$. *Significantly different from the EAC-control. FSignificantly different from cisplatin group. ${ }^{\Omega}$ Significantly different from other cirsiliol groups.

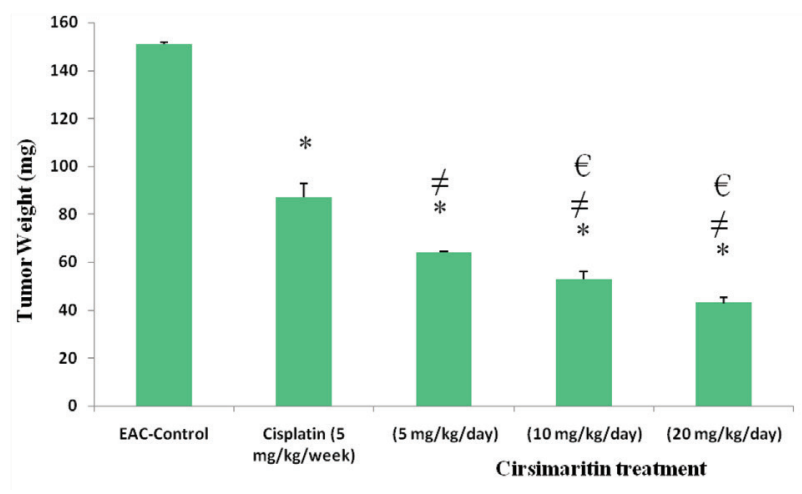

Figure 5. Effects of cisplatin and cirsimaritin on tumor weight in EACbearing mice. EAC: Ehrlich's ascites carcinoma. Values are expressed as the mean \pm SEM and data were analyzed using one-way ANOVA followed by Bonferroni's post hoc test at $P<0.05$. * Significantly different from the EAC-control. ${ }^{\ddagger}$ Significantly different from cisplatin group. ${ }^{2}$ Significantly different from cirsimaritin ( $5 \mathrm{mg} / \mathrm{kg} /$ day) group.

fragrantissima extract and the flavonoids significantly increased the TAC compared to EAC-control and cisplatin groups, especially cirsimaritin $(20 \mathrm{mg} / \mathrm{kg})$ group which normalized the antioxidant capacity (Table 1 ).

Histopathological examination

The histological assay was performed by $H \& E$ staining to determine the degree of inflammation, the shape of cells, the degree of infiltration and arrangement of tumor cells. EAC-control mice showed a tumor disc with subcutaneous necrotizing tumor formed of rounded and oval cells, with indistinct cell borders, scant cytoplasm, pleomorphic hyperchromatic nuclei, prominent nucleoli, and modest mitotic activity, arranged in solid sheets, infiltrating subcutaneous fat and muscle tissue (Figure 7). Scattered multinucleated giant cells and chronic inflammatory infiltrate as well as a few glandular-like arrangements of tumor cells were observed (arrows, Figure 7). The effect 


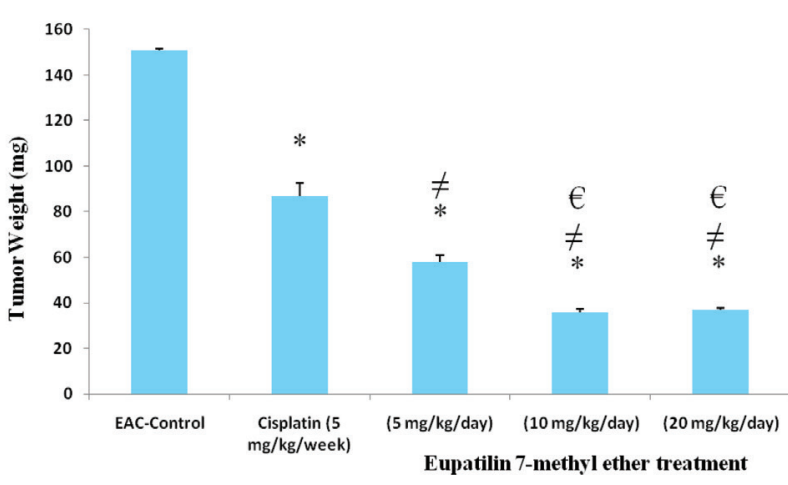

Figure 6. Effect of cisplatin and eupatilin 7-methyl ether on tumor weight in EAC-bearing mice. EAC: Ehrlich's ascites carcinoma. Values are expressed as the mean \pm SEM.and data were analyzed using one-way ANOVA followed by Bonferroni's post hoc test at $P<0.05$. *Significantly different from the EAC-control. ${ }^{\ddagger}$ Significantly different from cisplatin group. ${ }^{E}$ Significantly different from eupatilin 7 -methyl ether $(5 \mathrm{mg} / \mathrm{kg} / \mathrm{d})$ group.

of cisplatin $(5 \mathrm{mg} / \mathrm{kg})$ on the tumor was represented with areas of tumor necrosis and replacement with a chronic granulomatous inflammatory component, composed of lymphocytes, macrophages, epithelioid cells and multinucleated giant cells (Figure 7).

Achillea fragrantissima extract produced a better differentiation of tumor cells, with reduced nuclear pleomorphism and better formed tubular structures especially with high dose (Figure 7). Similarly, chrysosplenol D treatment showed decreased nuclear pleomorphism and atypia, however, no changes were observed in increasing dose. On the other hand, the cirsiliol treatment produced a significant tumor cell necrosis, on increasing the dose the tumor cells showed decreased nuclear pleomorphism with tumor cell necrosis and chronic inflammatory cell infiltrate. In addition, cirsiliol $(20 \mathrm{mg} / \mathrm{kg})$ produced a better differentiation of tumor cells, reduced nuclear pleomorphism, and glandular-like cell arrangements and an increase in the spindle cell differentiation component (Figure 7).

The cirsimaritin treatment produced a significant tumor cell necrosis and on increasing the dose the tumor cells showed better differentiation with decreased nuclear pleomorphism. Similarly, eupatilin 7-methyl ether groups produced a significant tumor cell necrosis areas, spindle cell differentiation became prominent with reduced nuclear pleomorphism and atypia (Figure 7).

\section{Discussion}

Flavonoids and other polyphenolic compounds separated from natural sources have been suggested to have antitumor properties both at the initiation and the promotion stages of carcinogenesis process (15). Therefore, the present study aimed to investigate the antitumor activity of $A$. fragrantissima extract and isolated methoxylated flavonoids cirsimaritin, chrysosplenol D, cirsiliol and eupatilin-7-methyl ether on EAC model in
Table 1. Effect of cisplatin, Achillea fragrantissima extract, chrysosoplenol $\mathrm{D}$, cirsiliol, cirsimaritin and eupatilin 7-methyl ether on serum tumor necrosis factor alpha (TNF-a) and total antioxidant capacity (TAC) levels in Ehrlich's ascites carcinoma (EAC) bearing mice

\begin{tabular}{|c|c|c|}
\hline Treatment Groups & TNF-a $(p g / m L)$ & $\mathrm{TAC}(\mathrm{mmol} / \mathrm{L})$ \\
\hline Normal control ( $5 \mathrm{~mL}$ saline $/ \mathrm{kg} / \mathrm{d}$ ) & $64 \pm 0.53^{*}$ & $21 \pm 1.04^{*}$ \\
\hline EAC-Control ( $5 \mathrm{~mL}$ saline $/ \mathrm{kg} / \mathrm{d})$ & $117 \pm 3.18$ & $2 \pm 0.09$ \\
\hline Cisplatin ( $5 \mathrm{mg} / \mathrm{kg} / \mathrm{wk})$ & $61 \pm 0.54^{*}$ & $8 \pm 0.09{ }^{*}$ \\
\hline A.fragrantissima extract $(100 \mathrm{mg} / \mathrm{kg} / \mathrm{d})$ & $76 \pm 4.5^{*}$ & $18 \pm 0.87^{* \neq \oplus}$ \\
\hline A.fragrantissima extract $(200 \mathrm{mg} / \mathrm{kg} / \mathrm{d})$ & $53 \pm 0.72 *$ & $13 \pm 0.2^{* \neq \oplus}$ \\
\hline Chrysosoplenol D $(5 \mathrm{mg} / \mathrm{kg} / \mathrm{d})$ & $61 \pm 0.64^{*}$ & $13 \pm 0.14^{* \neq \oplus}$ \\
\hline Chrysosoplenol D (10 mg/kg/d) & $66 \pm 0.71^{*}$ & $18 \pm 1.56^{*} \neq$ \\
\hline Chrysosoplenol D $(20 \mathrm{mg} / \mathrm{kg} / \mathrm{d})$ & $61 \pm 2.16^{*}$ & $14 \pm 0.08^{* \neq 0}$ \\
\hline Cirsiliol $(5 \mathrm{mg} / \mathrm{kg} / \mathrm{d})$ & $74 \pm 4.11^{*}$ & $21 \pm 0.11^{*}$ \\
\hline Cirsiliol $(10 \mathrm{mg} / \mathrm{kg} / \mathrm{d})$ & $63 \pm 0.46^{*}$ & $11 \pm 0.36^{*} \odot$ \\
\hline Cirsiliol $(20 \mathrm{mg} / \mathrm{kg} / \mathrm{d})$ & $44 \pm 0.57^{*} \neq \odot$ & $14 \pm 0.31^{* \neq 0}$ \\
\hline Cirsimaritin $(5 \mathrm{mg} / \mathrm{kg} / \mathrm{d})$ & $69 \pm 0.77^{*}$ & $13 \pm 0.11^{* \neq \oplus}$ \\
\hline Cirsimaritin $(10 \mathrm{mg} / \mathrm{kg} / \mathrm{d})$ & $72 \pm 3.79^{*}$ & 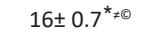 \\
\hline Cirsimaritin $(20 \mathrm{mg} / \mathrm{kg} / \mathrm{d})$ & $35 \pm 1.1^{*} \neq 0$ & $24 \pm 0.1^{*} \neq$ \\
\hline Eupatilin 7-methyl ether $(5 \mathrm{mg} / \mathrm{kg} / \mathrm{d})$ & $48 \pm 2.01^{*} \neq 0$ & $14 \pm 0.24^{* \neq \oplus \mathbb{C}}$ \\
\hline Eupatilin 7-methyl ether $(10 \mathrm{mg} / \mathrm{kg} / \mathrm{d})$ & $43 \pm 0.5^{*} \neq \mathbb{0}$ & $14 \pm 0.73^{* \neq \oplus}$ \\
\hline Eupatilin 7-methyl ether $(20$ mg/kg/d) & $46 \pm 1.85^{* \neq 0}$ & $14 \pm 0.7^{*} \neq \odot$ \\
\hline
\end{tabular}

EAC: Ehrlich's ascites carcinoma; TNF-a: tumor necrosis factor-a; TAC: total antioxidant capacity.

Values are expressed as the mean \pm SEM. and data were analyzed using one-way ANOVA followed by Bonferroni's post hoc test at $\mathrm{P}<0.05$.

*Significantly different from the EAC-control. \#Significantly different from cisplatin group. (CSignificantly different from the normal control group. Doses of the used drugs mentioned in the table.

mice. The present study described the antitumor activities and tried to explain the mechanisms underlying these activities.

Chromatographic separation and purification procedures led to the isolation of four methoxylated flavonoids, namely cirsiliol, chrysosplenol D, eupatilin 7-methyl ether and cirsimaritin. Cirsiliol was previously isolated from $A$. fragrantissima and showed cytotoxic activity against HepG2 cell lines (6). In addition, isolated cirsiliol from A. fragrantissima $(7,9)$. Isolation and identification of cirsimaritin and eupatilin 7-methyl ether from A. fragrantissima herb were also reported, previously (6). Similarly, chrysosplenol D was separated and identified in many previous studies $(16,17)$.

The main findings of this study are that $A$. fragrantissima extract exhibited antitumor activity in the EAC model in mice. In addition, the methoxylated flavonoids exhibited antitumor activity in the same model by a significant reduction of the tumor weight. In agreement with our findings, A. fragrantissima extract exerted its anticancer in chronic myeloid leukemia in-vitro (5).

According to our knowledge, this the first time to investigate the antitumor effect of A. fragrantissima extracts and its methoxylated flavonoids in an in-vivo 

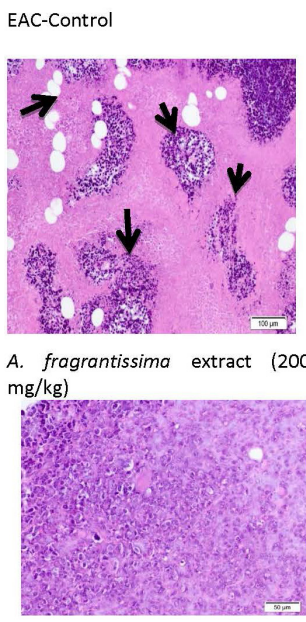

Cirsimaritin treatment

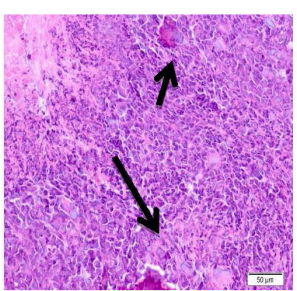

Cisplatin $(5 \mathrm{mg} / \mathrm{kg})$

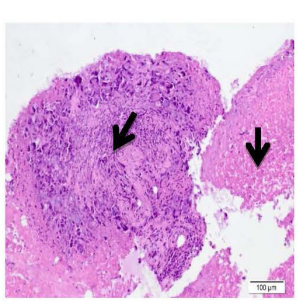

Chrysosplenol D treatment

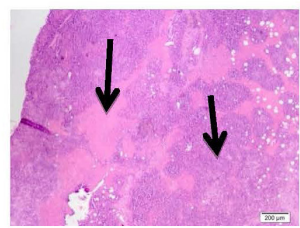

Eupatilin 7-methyl ether treatment

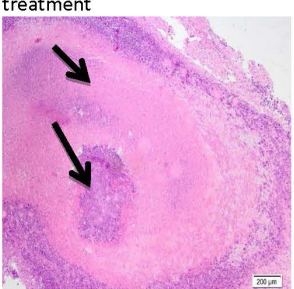

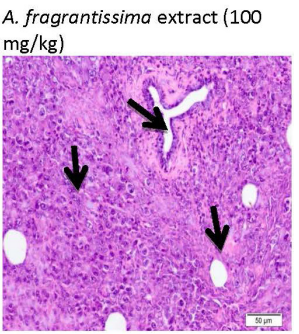

Cirsiliol treatment

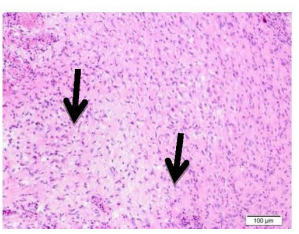

Figure 7. Effect of Cisplatin ( $5 \mathrm{mg} / \mathrm{kg} / \mathrm{wk}$, i.p.), Achillea fragantissima extract ( 100 or $200 \mathrm{mg} / \mathrm{kg} / \mathrm{d}$, p.o.), chrysosplenol D, cirsiliol, cirsimaritin and eupatilin 7-methyl ether treatments on EAC discs as shown by H\&E staining. Arrows in EAC group show rounded and oval cells, with indistinct cell borders, scant cytoplasm, pleomorphic hyperchromatic nuclei, prominent nucleoli, and modest mitotic activity, arranged in solid sheets, infiltrating subcutaneous fat and muscle tissue. Arrows in cisplatin group show necrotic tumor cells. Arrows in extract and isolated flavonoids illustrate better differentiation and decreased nuclear pleomorphism. The EAC discs from the mice were isolated, fixed in formalin, and embedded in paraffin. The histological assay was performed by H\&E staining. EAC: Ehrlich's ascites carcinoma. Photomicrographs are captured at 50-200 X magnification.

model of cancer. It seems that the A. fragrantissima extract is a cocktail extract containing compounds that interfere with the inflammation and tumor growing process as compounds with a free radical-scavenging activity that can enter the cells and react with reactive oxygen species, intracellularly. In this study, the extract and the methoxylated flavonoids exhibited a significant reduction in the level of TNF- $a$ and exhibited a significant increase in the total antioxidant capacity. This indicated the antioxidant properties of the extract which probably related to the presence of polyphenolic and flavonoid structures. In agreement with these results, Elmann et al reported that the anti-inflammatory effect of $A$. fragrantissima extract was due to the presence of antioxidant compounds present in the extract (18). Furthermore, Elmann et al reported that the inhibitory effect of the A. fragrantissima extract on the expression of the inflammatory molecules TNF-a molecules might be attributed to inhibition of NF$\mathrm{Kb}$ activation (18). So, the presence of flavonoids with higher concentrations may at least in part explain the observed antitumor activity.

The methoxylated flavonoids isolated from $A$. fragrantissima extract in this study exhibited antitumor activityby reducing tumor weight and this maybeattributed to the antioxidant properties of these compounds, which confirmed by the reduction of the serum level of TNF-a and increased serum level of TAC. In addition, our study showed that cirsiliol $(20 \mathrm{mg} / \mathrm{kg})$, cirsimaritin $(20 \mathrm{mg} / \mathrm{kg})$ and eupatilin 7-methyl ether exhibited the most powerful antioxidant activities. Many methoxylated flavonoids have demonstrated to possess antiproliferative properties (15). The higher proportion of spindle and glandular shaped cells found at a lower concentration of A. fragrantissima extract in this study indicate differentiation as an intermediate stage before the final death of cells. Also, the isolated methoxylated flavonoids in different doses decreased nuclear pleomorphism and atypia, especially cirsiliol $(20 \mathrm{mg} / \mathrm{kg})$ produced a better differentiation of tumor cells, reduced nuclear pleomorphism, and glandular-like cell arrangements and increase in the spindle cell differentiation component. Furthermore, these histological changes indicated the apoptotic induction produced upon using of extract and the flavonoids. In agreement with our findings, $A$. fragrantissima extract was reported that the main mechanism as anti-cancer attributed to the induction of cell differentiation and apoptosis (5).

\section{Conclusion}

Achillea fragrantissima extract and its isolated methoxylated flavonoids exhibited antitumor activity in the EAC model in mice. The antitumor effect of the extract and the flavonoids might be attributed to the antioxidant properties via reduction of TNF-a and increasing TAC. 
In addition, the antitumor activity of the extract and the flavonoids may be due to the induction of the apoptotic process inside the tumor. These findings support the effective therapeutic use of these natural compounds in the treatment of cancer.

\section{Acknowledgments}

We would like to thank Dr. Wael Ahmed Maher, lecturer of Pathology, Faculty of Medicine, Suez Canal University, Ismailia, Egypt, for his valuable assistance with $\mathrm{H} \& \mathrm{E}$ staining the analysis of the slides.

\section{Authors' contribution}

BMA, MMAA and SAA contributed to the idea of the study, its design, and interpretation. The extract and compounds were prepared by BMA. However, the experimental procedures were done by MMAA and BMA. The manuscript was prepared and written by BMA, MMAA, ESH, AKI and SAA then approved by all authors.

\section{Conflict of interests}

There is no conflict of interest.

\section{Ethical considerations}

All experimental protocols were approved by The Animal Care and Use Committee at the Faculty of Pharmacy, Suez Canal University. All procedures and techniques used in this study were in accordance with the National Institute of Health Guidelines for the Care and Use of Laboratory Animals (NIH, Department of Health and Human Services publication no. 85-23, revised 1985).

\section{Funding/Support}

Authors declare that there was no source of funding for this study.

\section{References}

1. Rajesh E, Sankari LS, Malathi L, Krupaa JR. Naturally occurring products in cancer therapy. J Pharm Bioallied Sci. 2015;7(Suppl 1):S181-3. doi: 10.4103/0975-7406.155895.

2. Amin AR, Kucuk O, Khuri FR, Shin DM. Perspectives for cancer prevention with natural compounds. J Clin Oncol. 2009;27(16):2712-25. doi: 10.1200/jco.2008.20.6235.

3. Saeidnia S, Gohari A, Mokhber-Dezfuli N, Kiuchi F. A review on phytochemistry and medicinal properties of the genus Achillea. Daru. 2011;19(3):173-86.

4. Si XT, Zhang ML, Shi QW, Kiyota H. Chemical constituents of the plants in the genus Achillea. Chem Biodivers. 2006;3(11):1163-80. doi: 10.1002/cbdv.200690119.

5. Alenad AM, Al-Jaber NA, Krishnaswamy S, Yakout SM, Al-Daghri NM, Alokail MS. Achillea fragrantissima extract exerts its anticancer effect via induction of differentiation, cell cycle arrest and apoptosis in chronic myeloid leukemia
(CML) cell line K562. J Med Plant Res. 2013;7(21):1561-7.

6. Bakr RO, Arafa RK, Al-Abd AM, Elshishtawy HM. Phenolics of Achillea fragrantissima growing in Egypt and its cytotoxic activity. J Med Plant Res. 2014;8(21):763-71. doi: $\quad 10.5897 / J M P R 2014.5437$.

7. Bartolotti N, Disouky A, Kalinski A, Elmann A, Lazarov O. Phytochemicals from Achillea fragrantissima are Modulators of AbetaPP Metabolism. J Alzheimers Dis. 2018;66(4):1425-35. doi: 10.3233/jad-180068.

8. Khafagy SM, Sabri NN, Soliman FS, Abou-Donia AH, Mosandl A. Isolation of two flavonoids from Achillea santolina L. growing in Egypt. Pharmazie. 1976;31(12):8945.

9. Mustafa EH, Abu Zarga M, Abdalla S. Effects of cirsiliol, a flavone isolated from Achillea fragrantissima, on rat isolated ileum. Gen Pharmacol. 1992;23(3):555-60. doi: 10.1016/0306-3623(92)90127-6.

10. Abd-Alhaseeb MM, Zaitone SA, Abou-El-Ela SH, Moustafa YM. Olmesartan potentiates the anti-angiogenic effect of sorafenib in mice bearing Ehrlich's ascites carcinoma: role of angiotensin (1-7). PLoS One. 2014;9(1):e85891. doi: 10.1371/journal.pone.0085891.

11. Al Abdan M. Alfa-lipoic acid controls tumor growth and modulates hepatic redox state in Ehrlich-ascites-carcinomabearing mice. ScientificWorldJournal. 2012;2012:509838. doi: $10.1100 / 2012 / 509838$.

12. Abd-Alhaseeb MM, Zaitone SA, Abou-El-Ela SH, Moustafa YM. Angiotensin (1-7) antagonist diminished the antitumor effect of Olmesartan in tumor cell lines grown in-vitro and in-vivo. Enliven Chall Cancer Detect Ther. 2014;1(1):1-7. doi: 10.18650/2376-046X.11002.

13. Silver DF, Piver MS. Effects of recombinant human erythropoietin on the antitumor effect of cisplatin in SCID mice bearing human ovarian cancer: a possible oxygen effect. Gynecol Oncol. 1999;73(2):280-4. doi: 10.1006/ gyno.1999.5368.

14. Koracevic D, Koracevic G, Djordjevic V, Andrejevic S, Cosic V. Method for the measurement of antioxidant activity in human fluids. J Clin Pathol. 2001;54(5):356-61. doi: $\quad 10.1136 /$ jcp.54.5.356.

15. Walle T. Methoxylated flavones, a superior cancer chemopreventive flavonoid subclass? Semin Cancer Biol. 2007;17(5):354-62. doi: 10.1016/j.semcancer.2007.05.002.

16. Valant-Vetschera KM, Wollenweber E. Exudate flavonoid aglycones in the alpine species of Achillea sect. Ptarmica: Chemosystematics of $A$. moschata and related species (Compositae-Anthemideae). Biochem Syst Ecol. 2001;29(2):149-59.

17. Deng Y, Chin YW, Chai HB, de Blanco EC, Kardono LB, Riswan S, et al. Phytochemical and Bioactivity Studies on Constituents of the Leaves of Vitex Quinata. Phytochem Lett. 2011;4(3):213-7. doi: 10.1016/j.phytol.2011.03.007.

18. Elmann A, Mordechay S, Erlank H, Telerman A, Rindner M, Ofir R. Anti-neuroinflammatory effects of the extract of Achillea fragrantissima. BMC Complement Altern Med. 2011;11:98. doi: 10.1186/1472-6882-11-98. 